\title{
Effect of non-ionizing radiation on the health of medical staff of magnetic resonance imaging rooms
}

\author{
Lyazat Ibrayeva $^{1}$, Olga Grebeneva ${ }^{2}$, Almagul Shadetova ${ }^{2}$, Dina Rybalkina ${ }^{1}$, Larissa Minbayeva ${ }^{1}$, Irina \\ Bacheva $^{1}$, Alexey Alekseyev ${ }^{2}$ \\ ${ }^{1}$ Department of Internal Diseases, Karaganda Medical University, Karaganda city, Republic of Kazakhstan \\ ${ }^{2}$ Institute of Public Health and Professional Health, Karaganda Medical University, Karaganda city, Republic of Kazakhstan
}

Received: 2021-04-21.

Accepted: 2021-07-16

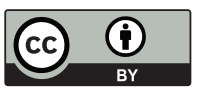

This work is licensed under a

Creative Commons Attribution 4.0 International License

J Clin Med Kaz 2021; 18(4):16-22

Corresponding author:

Dina Rybalkina.

E-mail: ystas666@list.ru;

ORCID: 0000-0002-2041-1259

\section{Abstract}

Working conditions of medical staff in magnetic resonance imaging rooms are associated with high levels of stationary magnetic fields and electromagnetic fields of various frequencies and increased work intensity. It can affect cognitive, psychological and hemodynamic changes of the body with health issues. It requires not only high professional training, but also compliance with safety measures, as well as monitoring of working conditions, health status and carrying out of medical and preventive measures.

Key words: Magnetic Resonance Imaging, medical staff, physical fields, functional changes, health status

\section{Introduction}

The Republic of Kazakhstan considers preservation of the working population health as one of the most important priorities of the state social policy. Medical community is especially concerned about intensive introduction of such insufficiently studied factors as alternating electromagnetic and constant magnetic fields into industrial and living environment. The lack of common understanding about the consequences of exposure to non-ionizing radiation to the health of workers is determined by frequency variety, intensity, multiplicity of exposure, duration and complexity of radiation. Pathological conditions and diseases caused by exposure of non-ionizing radiation are extremely diverse, individual and often not completely replicable in laboratory conditions for detailed study. Rapid and widespread introduction of technically complicated functional methods into medical diagnostic and treatment processes is currently due to the urgent need to intensify imaging to fight against the COVID-19 pandemic. This causes a certain degree of caution in relation to individual health not only for patients who undergo repeated examinations, but also for medical personnel.

Analysis of the results of a number of studies indicate a significant physiological "cost" of labor, both physical and mental health infringements in medical personnel of different structural units of medical and preventive organizations [1]. The professional conditionality of changes in health from the influence of physical factors is emphasized [2]. This entails the need for a special accounting system for the category of people from risk groups, the development of recommendations for the early diagnosis and prevention of identified diseases. One of the leading places in the morbidity of medical personnel is firmly occupied by diseases of the musculoskeletal system [3]. It is associated not only with an increase of the professional stress level, but also with the influence of complex climatic and ecological environmental factors. Among medical workers, a high prevalence of inverse-destructive behavioral risk factors and relatively low adherence to early diagnosis and treatment of preclinical manifestations of diseases was noted [4]. It requires the need to correct these factors. The influence of electromagnetic fields of industrial frequency and radio frequency range at the level of permissible values accompanied the activities of 6.5 and $3.3 \%$ of medical workers in diagnostic departments [5]. At the same time, the occupational factors parameters of physical nature do not exceed the permissible values. Medical examinations for employees of organizations using sources of ionizing radiation have a number of features, including necessity of "specialized" medical examination with the obligatory psychophysiological examination [6].

To highlight the existing problem, an analytical review of articles in electronic databases (PubMed, Web of Science, Scopus) for the period from 1990 to 2021 
was carried out. According to the basic keywords used for the literature search, about 500 sources were identified. 84 cited sources of literature on the research of domestic and foreign scientists (articles, monographs, research reports) were selected. Minimum percentile of journals in the Scopus database was 30, and maximum was 93 (average percentile for cited journals was 63.35). It should be noted that the publication activity on the studied topic is increasing over the time.

\section{Prevalence of MRI research in the world}

Every year, about 60 million of magnetic resonance imaging (MRI) scans are carried out around the world, allowing to obtain the necessary diagnostic information about structural disorders of the body without the use of ionizing radiation [7]. As MRI technology improves, areas of application are expanding and the number of patients exposed to magnetic fields increases [8]. Besides visualization of the condition of internal organs, the technology of brachytherapy under the visual control of MRI has expanded rapidly. This led to a change in the course of clinical examination, standardization of examination techniques and unification of adaptive determination of minimum required dose to facilitate targeted implantation [9]. High-quality MRI imaging has come to be used in hybrid treatment technology using radiation therapy on the implementation of special MRI simulator for assessing tumor response to adaptive treatment [10]. While using these techniques, medical personnel are exposed to various types of EMFs: static magnetic field (SMF) that constantly present in- and around the MRI scanner; timevarying electric fields arising during the movement of workers through the inhomogeneous SMF surrounding the scanner; radio frequency $(\mathrm{RF})$ pulses in the megahertz frequency range used to generate a signal; switchable gradient fields in the kilohertz frequency range that are applied to spatial coding [11]. A study of the working conditions of 145 MRI departments in the Netherlands revealed that about 7,000 people worked in rooms with an MRI scanner. 54\% were professionally exposed to electromagnetic fields (EMF) at least once a day and 9\% were regularly present in a room with a scanner during imaging [11].

The working conditions of medical personnel of MRI rooms are characterized by a complex of harmful factors: static magnetic field, increased labor intensity and severity, insufficient natural illumination, noise. The most unfavorable working conditions were observed in the diagnostic room when preparing a patient for examination. The levels of magnetic induction significantly exceed the maximum permissible levels (MPL). It requires preventive measures to ensure the hygienic safety of medical personnel [12]. Health care workers are exposed to various levels of field influences. They are determined by the characteristics of the workplace (type of scanner, MRI installation scheme), category of work, type of procedure and patient condition. In particular, radiologists, anesthesiologists, interventionists, nurses, service personnel and cleaners are exposed to SMF and time-varying electrical fields caused by movement. In this case, the influence of the gradient and radio frequency pulses occurs only in special cases. For example, during so-called dynamic examinations, in emergency cases, while examining pediatric patients or in the case of interventional medical procedures [13]. Hygienic working conditions of medical personnel in MRI rooms in Russian Federation are considered dangerous due to the effect of constant magnetic field (class 3.1-3.2) and due to noise level (class 3.1-3.2). The general assessment of the working conditions of medical personnel in MRI rooms corresponds to class 3.1-3.3 [14].

\section{Experience of studying of medical personnel health under the influence of non-ionizing radiation}

Numerous studies, empirical observations and patient reports indicate the possibility of relationship between EMF exposure and health problems. Review of epidemiological research on cancer, human reproduction, neurobehavioral responses, neurological, degenerative and heart diseases suggests an increase in the risks of their occurrence under the influence of magnetic fields [15]. In medical personnel exposed to a stationary magnetic field and EMF of RF in MRI rooms, change in the state of health is associated with poor cardiovascular and central nervous systems function. This indicates the tension of adaptive processes of the organism [16]. Affecting the body with various types of EMF (static, induced, variable, low-frequency and radiofrequency), MRI can cause nerve and muscle stimulation, local or systemic tissue heating, changes of blood flow.

Thus, researchers from Iran, while analyzing questionnaires for health reasons, found a statistically significant difference between the frequency of complaints of headaches and sleep problems among MRI workers and the control group $(\mathrm{P}=0.037$, $\mathrm{P}<0.001$, respectively). In addition, the incidence of myalgia, palpitations, fatigue, trouble concentrating, nervousness, and back pain was higher in MRI service personnel than in controls [17]. In operators working with high exposure scanners (3 Tl), the average number of detected health symptoms was higher compared to operators working with a lower exposure scanners $(1.5 \mathrm{Tl})$. At the same time, at the beginning of professional activity, MRI operators may experience more different symptoms of health disorders, neutralized in a few weeks and indicated some form of adaptation [18].

Transient symptoms of impaired health (dizziness, nausea, tinnitus and trouble concentrating) in MRI staff in the UK were reported in $4 \%$ of shifts and were associated with longer work in MRI departments [19]. MRI specialists in Holland, were at increased risk of accidents while driving and cycling (operating over a year, with odds ratio $\mathrm{OR}=2.13,95 \%$ CI $1.23-3.69$ ) [20]. Comparable risk was observed among employees of enterprises for the production of medical imaging devices [21]. Experts from Spain found that among 176 studied unfavorable incidents in patients in MRI rooms, $20.4 \%$ are specific risks inherent in MRI (burns, management of patients with contraindications), $69.9 \%$ are associated with contrast agents (allergies and side effects), 9.7\% - general risks (anxiety, injury) [22].

A high probability of adverse occupational exposure of static magnetic fields during MRI was observed in examining animals personnel [11]. MRI equipment uses the strongest magnetic field, which is constantly present in the MRI office, while gradient fields (frequencies in the $\mathrm{kHz}$ range) and radio frequency fields (frequencies in the $\mathrm{MHz}$ range) are generated only during the scan procedure [23]. Static magnetic flux density depends on the distance from MRI scanner. So, movement in a static field generates time-varying electric fields and currents in the body of the personnel. The impact of SMF on medical staff during their induced movement in the MRI room is accompanied by dizziness, increased heart rate, hypothermia and the appearance of a metallic taste in the mouth [24]. Shortterm influence of EMF can cause such effects as dizziness, nausea, metallic taste in the mouth when moving the body or head, sensation of flickering light in the field of vision, decreased labor productivity (changes in memory, hand-eye coordination), changes in blood pressure and heart rate within physiological variability and transient arrhythmias [25]. 
Some literary sources reported that static magnetic fields affect a number of structures in the human body (retina, pineal gland and paranasal sinus cells). However, these effects are not necessarily harmful or teratogenic / carcinogenic [26]. Although, biological mechanisms are not always clear and health hazards have not been confirmed some countries have adopted a "precautionary principle" or "prudent avoidance of exposure limits". Known endpoints of health disorders associated with low-frequency EMF (LMF) and/or ultrahigh radio frequency (RF) include pediatric leukemia, brain tumors, genotoxic effects, neurological effects and neurodegenerative diseases, immune dysregulation, allergic and inflammatory reactions, cancer breast, miscarriage and some cardiovascular effects [27].

Studying the state of health of medical personnel exposed to magnetic field in MRI rooms, Russian scientists found changes in functioning of cardiovascular and central nervous systems, which indicates the tension of adaptation processes due to the existing professionally negative factors [16]. Radiologists with an inserted intrauterine device (IUD) who were professionally exposed to EMF from MRI scanners reported more about abnormal uterine bleeding than their counterparts without an IUD or their non-irradiated counterparts with an IUD. In particular, physicians presented near the MRI scanner at the time of imaging showed an increased risk of dysfunctional uterine bleeding [28]. It was found that the average mineral content in the bones of the vertebrae and femoral neck, mineral density, and the average level of 25-hydroxyvitamin D3 were lower in MRI technicians than in the control group $(\mathrm{p}<0.01)$. The average calcium level of the MRI technician was higher than in the control group $(p<0.05)[29]$. Some scientific studies have shown genotoxic effects in cells after exposure to MRI, while others have shown none [30].

Long-term prospective or retrospective cohort studies of workers exposed to intensive fields in the workplace, during the operation or maintenance of MRI devices are recommended as a first priority for studying long-term disease risk, to identify potential biomarkers of cancer and neurological disease risk [31]. Long-term occupational exposure to LMF can lead to depression, stress, anxiety and poor quality sleep [32]. Subjects, exposed to long-term daily exposure to HMF had significantly higher risk of poor quality sleep compared to subjects with short daily exposure. Adjusted odds ratios were 1.68 (95\% CI: $1.18,2.39)$ and 1.57 (95\% CI: 1.10, 2.24), accordingly. The risk of poor quality sleep: 2.12 (95\% CI 1.23-3.66) [33]. High intensity and chronic exposure to ELF-MF causes an increase in corticosteroid secretion along with depressive and/or anxiety behavior, without an increase in the hypothalamic-pituitaryadrenal axis [34]. The effect of EMF of RF on the occurrence of acute cardiovascular diseases was only observed when exposed to MRI, included static and time-varying magnetic fields [35].

One of the factors affecting the health of medical workers (radiographers) is radio anxiety, accompanied by anxiety about their health due to radiation exposure. At the same time, radio anxiety increases with an increase of work experience [36]. $15.8 \%$ of medical personnel in the departments of radiation diagnostics are exposed to ionizing radiation. he health effects associated with exposure to EMF have been officially designated by World Health Organization (WHO) as electromagnetic sensitivity or idiopathic environmental intolerance (IEI). 2007 poll in Taiwan showed that the prevalence of IEI-EMF was $13.3 \%$, and in 2016 it dropped to $4.6 \%$. Moreover, this indicator was higher in women [37]. The purpose of monitoring of EMF side effects is to identify electrosensitive workers with increased susceptibility [38].

\section{Probabilistic mechanisms of MRI influence on medical personnel}

It is known that EMFs with a frequency of up to $10 \mathrm{MHz}$ in the body induce time-varying electric fields that can affect the electrical properties of living cells and change their function [39]. There is growing evidence that exposure to EMF has a significant effect on the ability to oxidative and nitrosative regulation, which may explain the change in susceptibility to EMF and the variety of symptoms associated with their exposure. [40].

Assessment of the MRI impact is not an easy task due to highly variable, difficultly predictable patterns of exposure depended on the characteristics of the workplace and personal behavior of each person. A recent large-scale study by the US National Toxicology Program (NTP) found statistically significant increase in cancer incidence in rodents exposed to Groupe Spécial Mobile (GSM) or Code Division Multiple Access (CDMA) signals for two years with increasing radiation intensity [41]. Yakimenko I. at al. (2011 y.) published data on carcinogenic effects of prolonged exposure to low-intensity microwave radiation [42]. MPL of EMFs cause cancer of brain and central nervous system, as well as other types of malignant neoplasms (for example, thyroid cancer) [43].

It was determined in epidemiological study that longterm exposure to occupational ELF-EMF leads to decrease of inflammatory biomarkers, including NF- $\kappa \mathrm{B}$ and IL-6. This suggests that ELF-EMF may affect the immune system [44].

Several studies have demonstrated that ELF-EMF-induced oxidative stress can lead to DNA damage [45] depending on the dose [46]. In the last decade, 8-OHdG has been frequently used as a biomarker for oxidative damage to DNA. Its presence can lead to accumulation of gene mutations and oncogenesis due to its molecular instability. The data indicate correlation between increased $8-\mathrm{OHdG}$ and carcinogenesis in various tumors [47, 48]. It was found that after professional irradiation in MRI devices $(500 \mu \mathrm{Tl}-3 \mathrm{Tl})$, the number of NK-cells in workers increased [49] and innate immunity activated. It is known that innate immune cells (neutrophils, macrophages, NK-cells, and other cells) perform their first-line protective functions and enhance the response by secreting chemokines, cytokines and other inflammatory mediators. They also promote the maturation and activation of adaptive cells of immune system ( $\mathrm{T}$ - and B-Lymphocytes), which carry out a powerful antigen-specific immune response against pathogens [50].

\section{Perspective ways to reduce the adverse effects of MRI on health}

The maximum magnetic flux density associated with the movement of workers near the MRI scanners, depending on the change of flux density over time, may exceed both the high level of exposure to the whole body and the level of exposure to limbs according to the revised Directive (International Commission on Non-Ionizing Radiation Protection (ICNIRP) 2013 / European Union (EU)). However, exposure limits do not apply only for MRI workers [23]. Factual data are compared with other sources of magnetic fields at the workplace and show why the European Commission decided to propose them as an exception. The calculated $1 \mathrm{~Hz}$ induced electric field associated with movement can also exceed the health impact limits in some scenarios of exposure to both the central and peripheral nervous systems.

The ICNIRP recommended the basic standards of permissible exposure. The Directive 2013/35 UE states that 2 levels of magnetic fields are permissible: with frequencies from 
1 to $400 \mathrm{~Hz}$ when exposed to the "central nervous system" (magnetophosphenes) and three times exceeding to the limbs [51]. This is applicable for workers who install, test, use, develop, maintain or research related MRI equipment. According to the study of the Nofer Medical Institute (Poland), the exposure of medical nurses to EMFs in the $0-300 \mathrm{GHz}$ range, emitted from MRI apparatus, was classified as appropriated to the Polish hygiene standards and assessed as safe [52]. In the Republic of Kazakhstan (RK), the permissible level of magnetic induction intensity of the SMF is $10 \mathrm{mTl}$ (with a general exposure) or 15 $\mathrm{mTl}$ (with a local exposure) with an 8 hour shift [53]. It is known that higher intensive field of MRI provide a higher signal-tonoise ratio and better spatial resolution. This results in better visualization of anatomical details, reduction of scanning time, and appearance of new unexpected and possibly unsafe working conditions [54]. Publications that specify maximum exposure values for specific frequencies to compare individual exposures with acceptable action levels of radiation (ICNIRPs) have been presented in a review [55]. The SMF inside MRI scanner or near certain places of MRI scanner $(1.5 \mathrm{Tl}, 2 \mathrm{Tl}$ and $4 \mathrm{Tl})$ can cause the formation of current density and electric fields that exceed the relevant standards of EU, ICNIRP and the Institute of Electrical and Electronics Engineers (IEEE). This was observed both during routine procedures for patients and during exposure to pulsed magnetic fields or their combinations while moving through surrounding space [56].

To determine the true exposure to EMF, it is necessary to carry out individual measurements in real time and space, using, for example, personal exposure- meters [57]. The results of carried out inspection measurements of 20 MRI devices $(0.2$ - $2.0 \mathrm{Tl}$ ) confirm the need to monitor the impact of MRI at the workplace during the entire shift. It is caused by the influence of time-varying magnetic field pulses (gradient field) arising during examination of the patient. The level of worker exposure depends on both the magnet type and ergonomic design of every MRI device [58]. Similar studies were conducted on 98 participants in the UK. Using dosimeters it was found that at the workplaces of not entering the MRI scanner room during imaging staff, the geometric mean peak of SMF and time-varying magnetic field (TVMF) were $448 \mathrm{mTl}$ and $1083 \mathrm{mTl}$, respectively [59].

Using portable magnetic field dosimeters for working with MRI devices personnel (Netherlands) it was found that, on average, $3.7 \%$ of time of the work shift the subjects were exposed to EMF. Average and peak exposure levels while working indoors with an MRI scanner were highest among technicians and radiographers and lowest among cleaning staff and anesthetists. It was noted that height of employee is negatively associated with measured levels of exposure $[60,61]$. Researchers from Italy found that the average values of time spent by radiologists to place the patient and remove the patient out of the area of X-ray examination were 220 and 127 seconds, respectively. The maximum intensity of static field during the patient's placement could achieve $500 \mathrm{mTl}$. So, part of time with magnetic flux density above $200 \mathrm{mTl}$ was about $31 \%$. All respondents wore Teslameter sensor at the chest level on the closest to the scanner zone side [62]. MRI scanning of head or neck showed the highest level of average peak magnetic field [63]. Influence of caused by movement induced electric fields from MRI scanner (1.5 Tl, $4 \mathrm{Tl}$ and $7 \mathrm{Tl})$ was modeled on the phantoms of male and female bodies. It was proved, that the person cannot be closer than $0.5 \mathrm{~m}$ in the axial direction form the MRI scanner with magnetic field intensity 1.5-7 Tl. To comply with the standards, the speed of movement of person in the SMF should not exceed $1 \mathrm{~m} / \mathrm{sec}$ [64]. In [65], the SMF was measured (magnetic flux density) near two MRI scanners $(1.5 \mathrm{Tl})$ during imaging. A model of movement in spatially varying magnetic field was created. It was found, that the whole body exposure from being near the front side of magnet exceed the limits specified in the EU Directive. Wherein the speed of movement should be limited to $1 / 5$ of normal walking speed. Compliance with exposure limits ensures that MRI workers are protected from the acute effects of EMF (dizziness, stimulation of excitable tissues). Long-term exposures can lead to cumulative harmful effects on personnel, including carcinogenic ones, which can be assessed by structural and numerical indicators of chromosomal aberrations [66].

It should be noted that measurements and calculations performed at specific limited set of workplaces does not exclude the possibility of higher impacts at other workplaces. Awareness and risk knowledge about work with MRI equipment, about methods of patient and staff protecting remain insufficient at the present time. It requires further study and bringing to the working staff notice [67].

To reduce the harmful effects of MRI factors on the health of personnel, a number of administrative measures have been proposed as protection (adherence to a strict work schedule, modification of scanners), the use of protective equipment and keeping self-monitoring diaries for health state [24]. Slow movement of personnel in an intensive EMF (2-8 Tl) and an emerging electric field (more than $1 \mathrm{~Hz}$ ) can prevent the occurrence of various sensory sensations and dizziness. Work with intensity of more than $8 \mathrm{Tl}$, when stimulation of peripheral nervous system is possible, should be limited [68]. At the same time, headache, sleep problems, slowing down responses to irritants and memory impairment can appear even with an MRI intensity of 1.5 Tl [69]. Similar changes were observed in 867 subjects, including exposed to EMF workers with changes of oxidative stress after exposure to EMF [70]. Green tea polyphenol supplementation (GTPS) has been used to reduce oxidative stress by individuals experiencing oxidative stress from EMF due to profession.

To improve the safety of personnel and patients during MRI examinations, it is recommended to minimize the number and duration of exposures to SMF. It is necessary to assess the feasibility of the procedure, to pay attention to the quality of the resulting image to avoid unnecessary repetition of the procedure. Continuous training and certification of staff is mandatory [71], because the staff of MRI rooms is prone to a false sense of security [24].

Working with MRI requires strict adherence to safety principles regarding access and structured surveillance. Patients, staff and doctors being in close proximity from the source of SMF may be in potentially dangerous situations for health, possibly with damage of equipment. It is possible in the presence of metal objects, jewelry and implants near the MRI scanner [72]. The MRI imaging technique poses a serious risk to personnel. Preparing the staff member it is necessary to pay attention to safety training [73], correct patient management in compliance with communicative norms, ensuring and maintaining confidentiality $[74,75]$. Strict adherence to safety rules by personnel around the MRI is just as important as controlling the level of tension. It is necessary to develop theoretical models and dosimetry of SMF near MRI (1.5 Tl and $3 \mathrm{Tl})$ under normal operating conditions, during its maintenance (replacement of elements), in emergency situations [76]. Also, to ensure the safety of patient management, a reasonable design of MRI scanners and its location, provision of the necessary premises for personnel [77], a clear marking of the floor in the room, limitation of the speed of body movement and head movements are required [78]. 


\section{Conclusion}

Expanding the scope of MRI increases the number of medical and technical personnel with risk of exposure to EMF and noise at the workplace. This requires further hygienic study of the features of the amplitude-frequency and temporal parameters of the magnetic fields created by the gradient coils of the MRI, selection of adequate controlled parameters for their hygienic assessment under various operating modes [79, 80]. High magnetic flux density and internal electric field intensity are observed in devices for magnetic stimulation. RF fields can be exceeded near diathermy devices, during electrosurgical procedures and hyperthermia [81]. Listed above determines the relevance of further research of adverse effects of nonionizing radiation on the health of medical workers in order to clarify hygiene standards, safety measures and development of corrective measures.

Disclosures: There is no conflict of interest for all authors.

Acknowledgements: We express our gratitude to the Medical University of Karaganda for providing access to the Scopus and Web of Science databases.

Funding: This research has been funded by the Science Committee of the Ministry of Education and Science of the Republic of Kazakhstan (Grant No. AP09259923, «Identification of the negative impact of a complex of non-ionizing radiation on the human body (on the example of medical personnel)").

\section{References}

1. Semenova VN, Galuzo NA, Chirkova OG. About problems of studying the health of medical personnel [in Russian] Med Tr Prom Ekol. 2019; 9:744-744. doi: 10.31089/1026-9428-2019-59-9-744-745.

2. Kosarev VV, Babanov SA. Occupational diseases of medical workers from exposure to physical factors [in Russian]. Therapevt. 2010; $11: 28-36$.

3. Ermolina TA, Martynova NA, Kuzmin AG. Features of morbidity from locomotory system diseases in medical staff ers [in Russian]. Med Tr Prom Ekol. 2018; 7:61-64. doi: 10.31089/1026-9428-2018-7-61-64.

4. Larina VN, Glibko KV, Arakelov SE, Kasaeva DA. Behavioral risk factors, medical awareness and adherence to treatment of medical workers of a multidisciplinary city clinical hospital [in Russian]. Med Tr Prom Ekol. 2020; 5:305-310. doi: 10.31089/1026-9428-202060-5-305-310.

5. Dubel EV, Unguryanu TN. Hygienic assessment of working conditions for medical personnel in clinical and paraclinical departments of the hospital [in Russian]. Gigiena $i$ Sanitaria. 2016, 1(95):53-57. doi: 10.18821/0016-9900-2016-95-1-53-57.

6. Kretov AS, Bushmanov AY, Udalov YD. Actual issues of medical examinations of workers in organizations using sources of ionizing radiation [in Russian]. Med Tr Prom Ekol. 2019; 9:663-663. doi: 10.31089/1026-9428-2019-59-9-663-664.

7. Robbie DW. Occupational exposure in MRI. Br J Radiol. 2012; 85(1012):293-312. doi: 10.1259/bjr/30146162.

8. Coskun O. Magnetic resonance imaging and safety aspects Toxicol Ind Health. 2011; 27:307. doi: 10.1177/0748233710386413)

9. Tharmalingam H, Alonzi R, Hoskin PJ. The Role of Magnetic Resonance Imaging in Brachytherapy. Clinical Oncology. 2018; 30(11):728-736. doi: 10.1016/j.clon.2018.07.024.

10. Rai R, Kumar S, Batumalai V, Elwadia D, Ohanessian L, Juresic E. et al. The integration of MRI in radiation therapy: collaboration of radiographers and radiation therapists Journal of Medical Radiation Sciences. 2017; 64(1):61-68. doi: 10.1002/jmrs.225.

11. Schaap K, Christopher-De Vries Y, Slottje P, Kromhout H. Inventory of MRI applications and workers exposed to MRI-related electromagnetic fields in the Netherlands. Eur J Radiol. 2013; 82:2279-85. doi: 10.1016 / j.ejrad.2013.07.023.

12. Egorova A.M., Mokoyan B.O., Lutsenko L.A. Some aspects of revealing health risk factors in medical personnel working with magnetic resonance tomographs [in Russian]. Med Tr Prom Ekol. 2017; 2:34-37.

13. Karpowicz J, Gryz K. Health Risk Assessment of Occupational Exposure to a Magnetic Field From Magnetic Resonance Imaging Devices. Int J Occup Saf Ergon. 2006; 12:155-167. doi: 10.1080 / 10803548.2006.11076679.

14. Mokoian BO. Hygienic characteristics of occupation for medical personnel working with magnetic resonance tomographs [in Russian]. Med Tr Prom Ekol. 2012; (3): 34-36. PMID: 22702134.

15. Knave B. Electromagnetic fields and health outcomes Ann Acad Med Singapore. 2001; 30(5):489-93. PMID: 11603131.

16. Mamchik NP, Mokoyan BO, Kameneva OV, Gabbasova NV. Health state of medical personnel in MRI- tomography offices [in Russian]. Med Tr Prom Ekol. 2016; 7:9-13. PMID: 30351640.

17. Ghadimi-Moghadam A, Mortazavi SMJ, Hosseini-Moghadam A, Haghani M, Taeb S, Hosseini MA. et al. Does Exposure to Static Magnetic Fields Generated by Magnetic Resonance Imaging Scanners Raise Safety Problems for Personnel? J Biomed Phys Eng. 2018; 8(3):333-336. PMID: 30320037.

18. Zanotti G, Ligabue G, Korpinen L, Gobba F. Subjective symptoms in Magnetic Resonance Imaging operators: prevalence, short-term evolution and possible related factors. Med Lav. 2016; 107(4):263-70. PMID: 27464899.

19. de Vocht F, Batistatou E, Mölter A, Kromhout H, Schaap K, van Tongeren M. et al. Transient health symptoms of MRI staff working with 1.5 and 3.0 Tesla scanners in the UK. Eur Radiol 2015; 25:2718-2726. doi: 10.1007/s00330-015-3629-z.

20. Huss A, Schaap K, Kromhout H. MRI-related magnetic field exposures and risk of commuting accidents - A cross-sectional survey among Dutch imaging technicians Environ Res. 2017; 7(156):613-618. doi: 10.1016/j.envres.2017.04.022.

21. Bongers S, Slottje P, Portengen L, Kromhout H. Exposure to static magnetic fields and risk of accidents among a cohort of workers from a medical imaging device manufacturing facility. Magn Reson Med. 2016; 75(5):2165-2174. doi: 10.1002/mrm.25768.

22. Capelastegui A, Fernández-Cantón G, Fernández-Ruanova B. The safety of magnetic resonance imaging: An analysis based on a review of incidents at the Osatek Center [Seguridad en resonancia magnética: Análisis basado en una revisión de incidentes en Osatek] Radiologia. 2006; 48(4): 225-234. doi: 10.1016/S0033-8338(06)73159-9.

23. Schenck JF. Health and safety effects of static magnetic fields: In book Shellock FG, editor. ed. Magnetic resonance procedures: impact on health and safety. Boca Raton, Florida: CRC Press; 2001. PP. 1-29. doi: 10.1201/9781420041569.ch1. 
24. Hansson B, Olsrud J, Wilén J, Owman T, Höglund P, Björkman-Burtscher IM. Swedish national survey on MR safety compared with CT: a false sense of security? European Radiology. 2020; 30(4):1918-1926. doi: 10.1007/s00330-019-06465-5.

25. Stam R, Yamaguchi-Sekino S. Occupational exposure to electromagnetic fields from medical sources. Ind Health. 2018; 56(2):96-105. doi: 10.2486/indhealth.2017-0112

26. Schenck JF. Physical interactions of static magnetic fields with living tissues. Progress in Biophysics and Molecular Biology. 2005; 87(2-3):185-204. doi: 10.1016/j.pbiomolbio.2004.08.009.

27. Hardell L, Sage C. Biological effects from electromagnetic field exposure and public exposure standards. Biomed Pharmacother. 2008; 62(2):104-9. doi: 10.1016/j.biopha.2007.12.004.

28. Huss A, Schaap K, Kromhout H. A survey on abnormal uterine bleeding among radiographers with frequent MRI exposure using intrauterine contraceptive devices. Magn Reson Med. 2018; 79(2):1083-1089. doi: 10.1002/mrm.26707.

29. Güngör HR, Ok N, Akkaya S, Akkaya N. Manyetik rezonans görüntüleme cihazlarının oluşturduğu statik manyetik alanın çalışanların kemik sağlığı üzerine olumsuz etkisi var mıdır? [Turkish]. Are there any adverse effects of static magnetic field from magnetic resonance imaging devices on bone health of workers? Eklem Hastalik Cerrahisi. 2014; 25(1):36-41. doi: 10.5606/ehc.2014.08. PMID: 24650383.

30. Frankel J, Wilén J, Hansson Mild K. Assessing Exposures to Magnetic Resonance Imaging's Complex Mixture of Magnetic Fields for In Vivo, In Vitro, and Epidemiologic Studies of Health Effects for Staff and Patients. Front Public Health. 2018; 6:66. doi: 10.3389/ fpubh.2018.00066.

31. Scientific Committee on Emerging Newly Identified Health Risks. Opinion on the potential health effects of exposure to electromagnetic fields. Bioelectromagnetism. 2015; 36:480-484. doi: 10.1002 / bem.21930).

32. Bagheri Hosseinabadi MB, Khanjani N, Ebrahimi MH, Haji B, Abdolahfard M. The effect of chronic exposure to extremely lowfrequency electromagnetic fields on sleep quality, stress, depression and anxiety. Electromagn Biol Med. 2019; 38(1):96-101. doi: 10.1080 / 15368378.2018 .154566$.

33. Liu H, Chen G, Pan Y, Chen Z, Jin W, Sun C. at all. Occupational Electromagnetic Field Exposures Associated with Sleep Quality: A Cross-Sectional Study. PLoS ONE. 2014; 9(10):e110825. doi: 10.1371/journal.pone.011082.

34. Kitaoka K, Kitamura M, Aoi Sh, Shimizu N, Yoshizaki K. Chronic exposure to an extremely low-frequency magnetic field induces depression-like behavior and corticosterone secretion without enhancement of the hypothalamic-pituitary-adrenal axis in mice Bioelectromagnetics. 2013; 34(1):43-51. doi: 10.1002 / bem. 2174.

35. Jauchem JR. Exposure to extremely low-frequency electromagnetic fields and radiofrequency radiation: cardiovascular effects in humans. Int Arch Occup Environ Health. 1997; 70(1):9-21. doi: 10.1007/s00420005018.

36. Gatiyatullina LL. The factors affecting medical professionals health [in Russian]. Kazan medical journal. 2016; 97(3):426-431. doi: 10.17750/KMJ2016-426.

37. Huang PC, Cheng MT, Guo HR. Representative survey on idiopathic environmental intolerance related to electromagnetic fields in Taiwan and comparison with international literature. Environmental Health. 2018; 17(1):5. doi: 10.1186 / s12940-018-0351-8.

38. Modenese A, Gobba F. Occupational Exposure to Electromagnetic Fields and Health Surveillance According to the European Directive 2013/35/EU Int J Environ Res Public Health. 2021; 18(4):1730. doi: 10.3390/ijerph18041730.

39. Reilly JP. Applied Bioelectricity. From Electrical Stimulation to Electropathology. Springer-Verlag New York, 1998. 563 p. doi: 10.1007/978-1-4612-1664-3.

40. Belyaev I, Dean A, Eger H, Hubmann G, Jandrisovits R, Kern M. et al. EUROPAEM EMF Guideline 2016 for the prevention, diagnosis and treatment of EMF-related health problems and illnesses. Rev Environ Health. 2016; 31(3):363-97. doi: 10,1515 / reveh-2016-0011.

41. Wyde M, Cesta M, Blystone C, Elmore S, Foster P, Hooth M. et al. Report of Partial Findings from the National Toxicology Program Carcinogenesis Studies of Cell Phone Radiofrequency Radiation in Hsd: Sprague Dawley® SD rats (Whole Body Exposures) bioRxiv. 2016; 055699. doi: 10.1101/055699.

42. Yakimenko I, Sidorik E, Kirilenko S, Chekhun V. Long-term exposure to microwave radiation provokes cancer growth: data from radars and mobile communication systems [in Russian]. Oncol experience. 2011; 33:62-70.

43. Carlberg M, Hedendahl L, Ahonen M, Koppel T, Hardell L. Increasing incidence of thyroid cancer in the Nordic countries with main focus on Swedish data. BMC Cancer. 2016; 16(7):426. doi: 10.1186 / s12885-016-2429-4.

44. Wang Z, Fei Y, Liu H, Zheng Sh, Ding Z, JinW. Effects of electromagnetic fields exposure on plasma hormonal and inflammatory pathway biomarkers in male workers of a power plant. Int Arch Occup Environ Health. 2016; 89:33-42.

45. Wolf FI, Torsello A, Tedesco B, Fasanella S, Boninsegna A, D'Ascenzo M. et al. Extremely low frequency $50 \mathrm{~Hz}$ electromagnetic fields enhance cell proliferation and DNA damage: possible involvement of the redox mechanism. Biochem Biophys Acta. 2005; 1743:120-129.

46. Ivancsits S, Diem E, Jahn O, Rüdiger HW, Intermittent extremely low frequency electromagnetic fields cause DNA damage in a dosedependent way. Int Arch Occup Environ Health. 2003; 76:431-436.

47. Foksinski M, Kotzbach R, Szymanski W, Olinski R. The level of typical biomarker of oxidative stress 8-hydroxy-2'-deoxyguanosine is higher in uterine myomas than in control tissues and correlates with the size of the tumor. Free Radical Biology \& Medicine. 2000; 29:597-601.

48. Matsui A, Ikeda T, Enomoto K, Hosoda K, Nakashima H, Omae K. et al. Increased formation of oxidative DNA damage, 8-hydroxy2'-deoxyguanosine, in human breast cancer tissue and its relationship to GSTP1 and COMT genotypes. Cancer Lett. 2000; 151:87-95.

49. Tuschl H., Neubauer G, Schmid G, Weber E, Winker N. Occupational exposure to static, ELF, VF and VLF magnetic fields and immune parameters Int J Occup Med Environ Health. 2000; 13(1):39-50. PMID: 10846844.

50. Frahm J, Mattsson MO, Simkó M. Frahm J, Mattsson MO, Simko M. Exposure to ELF magnetic fields modulate redox related protein expression in mouse macrophages. Toxicol Lett. 2010; 192(3):330-336. doi: 10.1016 / j.toxlet.2009.11.010.

51. Israel M, Ivanova M, Zaryabova V, Ivanova P, Topalova I, Petkova H. New aspects of legislation concerning EMF exposure to medical personnel in MRI. RAD Conference Proceedings, 2014:235-238. doi: 2-s2.0-85057759271.

52. Zmyślony M, Mamrot P, Politański P. Exposure of nurses to electromagnetic fields Ekspozycja pielęgniarek na pola elektromagnetyczne. Medycyna Pracy. 2004; 55(2):183-187. doi: 2-s2.0-16544390527. 
53. Decree of the Ministry of National Economy of the Republic of Kazakhstan "On Approval of Hygienic Standards for Physical Factors Influencing Human" dated February 28, 2015 № 169.

54. Kim SJ, Kim KA. Safety issues and updates under MR environments. European Journal of Radiology. 2017; 89:7-13. doi: 10.1016/j. ejrad.2017.01.010.

55. Stam R. The Revised Electromagnetic Fields Directive and Worker Exposure in Environments with High Magnetic Flux Densities. Annals of Occupational Hygiene. 2014; 58(5):529-541. doi: 10.1093/annhyg/meu010.

56. Fuentes MA, Trakic A, Wilson SJ, Crozier S. Analysis and measurements of magnetic field exposures for healthcare workers in selected MR environments IEEE. Transactions on Biomedical Engineering. 2008; 55(4):1355-1364. doi: 10.1109/TBME/2007.913410.

57. Gajšek P, Ravazzani P, Grellier J, Samaras T, Bakos J, Thuróczy G. Review of Studies Concerning Electromagnetic Field (EMF) Exposure Assessment in Europe: Low Frequency Fields (50 Hz-100 kHz) Int. J. Environ. Res. Public Health. 2016; 13(9):875. doi: 10.3390/ijerph13090875.

58. Karpowicz J, Gryz K. Health Risk Assessment of Occupational Exposure to a Magnetic Field from Magnetic Resonance Imaging Devices. Int J Occup Saf Ergon. 2006; 12(2):155-67. doi: 10,1080 / 10803548.2006.11076679.

59. Batistatou E, Mölter A, Kromhout H, van Tongeren M, Crozier S, Schaap K. et al. Personal exposure to static and time-varying magnetic fields during MRI procedures in clinical practice in the UK. Occupational and environmental medicine. 2016; 73(11):779-786. doi: 10.1136oemed-2015-103194.

60. Schaap K, Christopher-De Vries Y, Crozier S, De Vocht F, Kromhout H. Exposure to static and time-varying magnetic fields from working in the static magnetic stray fields of MRI scanners: a comprehensive survey in the Netherlands. Ann Occup Hyg. 2014; 58(9):1094-110. doi: 10.1093/annhyg/meu057.

61. Schaap K, Christopher-De Vries Y, Cambron-Goulet É, Kromhout H. Work-related factors associated with occupational exposure to static magnetic stray fields from MRI scanners Magn Reson Med. 2016; 75(5):2141-55. doi: 10.1002/mrm.25720.

62. Moro L, Alabiso F, Parisoli F, Frigerio F. Experimental evaluation of the occupational exposure to static magnetic fields on a $3 \mathrm{~T}$ magnetic resonance scanner [in Italian.]. G Ital Med Lav Ergon. 2013; 35(1):26-31. PMID: 23798231.

63. Yamaguchi-Sekino S, Nakai T, Imai S, Izawa S, Okuno T. Occupational exposure levels of static magnetic field during routine MRI examination in 3T MR system Bioelectromagnetics. 2014; 35(1):70-5. doi: 10.1002/bem.21817.

64. Crozier S, Trakic A, Wang H, Liu F. Numerical study of currents in workers induced by body-motion around high-ultrahigh field MRI magnets. Journal of Magnetic Resonance Imaging. 2007; 26(5):1261-1277. doi: 10.1002/jmri.21160.

65. Riches SF, Collins DJ, Charles-Edwards GD, Shafford JC, Cole J, Keevil SF, Leach MO. Measurements of occupational exposure to switched gradient and spatially-varying magnetic fields in areas adjacent to $1.5 \mathrm{~T}$ clinical MRI systems. Journal of Magnetic Resonance Imaging. 2007; 26(5):1346-1352. doi: 10.1002/jmri.21139.

66. Luzhna L, Kathiria P, Kovalchuk O. Micronuclei in genotoxicity assessment: from genetics to epigenetics and beyond. Front. Genet., 2017; 5:344. doi: 10.3389 / fpubh.2017.00344.

67. Alghamdi A, Alsharari Z, Almatari M, Alkhalailah M, Alamri S, Alghamdi A. et al. Radiation Risk Awareness Among Health Care Professionals: An Online Survey. Journal of Radiology Nursing. 2020; 39(2):132-138. doi: 10.1016/j.jradnu.2019.11/004.

68. Jokela K., Saunders RD. Physiologic and dosimetric considerations for limiting electric fields induced in the body by movement in a static magnetic field. Health Physics. 2011; 100(6):641-653. doi: 10.1097/HP.0b013e318202ec7e.

69. Ghadimi-Moghadam A, Mortazavi SMJ, Hosseini-Moghadam A, Haghani M, Taeb S, Hosseini MA. et al. Does exposure to static magnetic fields generated by magnetic resonance imaging scanners raise safety problems for personnel? Journal of Biomedical Physics and Engineering. 2018; 8(3):333-336. doi: 10.122086/jbpe.v0i0.653.

70. Zhang Y, Zhang D, Zhu B, Zhang H, Sun Y, Sun Ch. Effects of dietary green tea polyphenol supplementation on the health of workers exposed to high-voltage power lines Environ Toxicol Pharmacol. 2016; 46:183-187. doi: 10.1016/j.etap.2016.07.016.

71. Dobbins JT, Frush DP, Kigongo CJN, MacFall JR, Reiman RE, Trahey GE. Medical imaging safety in the developing world. Radiology in Global Health: Strategies, Implementation, and Applications. 2014; 9781461406044:41-60. doi: 10.1007/978-1-4614-0604-4_7.

72. Cross NM, Hoff MN, Kanal KM. Avoiding MRI-Related Accidents: A Practical Approach to Implementing MR Safety. Journal of the American College of Radiology. 2018; 15(12):1738-1744. doi: 10.1016/j.jacr.2018.06.022.

73. Westbrook C, Talbot J. What do MRI radiographers really know? European Journal of Radiography. 2009; 1(2):52-60. doi: 10.1016/j. ejradi.2009.04.001

74. Munn Z, Pearson A, Jordan Z, Murphy F, Pilkington D, Anderson A. Addressing the Patient Experience in a Magnetic Resonance Imaging Department: Final Results from an Action Research Study. Journal of Medical Imaging and Radiation Sciences. 2016; 47(4):329-336. doi: 10.1016/j.jmir.2016.04.007.

75. Crisp S, Dawdy K. Building a Magnetic Resonance Imaging Safety Culture from the Ground Up. Journal of Medical Imaging and Radiation Sciences. 2018; 49(1):18-22. doi: 10.1016/j.jmir.2017.10.005

76. Acri G., Inferrera P, Denaro L, Sansotta C, Ruello E, Anfuso C. et al. dB/dt evaluation in MRI sites: Is ICNIRP threshold limit (for workers) exceeded? International Journal of Environmental Research and Public Health. 2018; 15(7):e1298. doi: 10.3390/ijerph15071298

77. Gilk T, Kanal E. Planning an MR suite: What can be done to enhance safety? Journal of Magnetic Resonance Imaging. 2015; 42(3):566-571. doi: 10.1002/jmri.24794.

78. Leitgeb N, Gombotz H. Arbeiten im Magnetfeld von Ultrahochfeld-MRT. Working in the magnetic field of ultrahigh field MRI [German]. Radiologe. 2013; 53(5):429-33. doi: 10.1007/s00117-013-2506-5.

79. Pokhodzey L.V., Rudneva E.A., Paltzev Yu.P. Investigation of the spectral characteristics of low-frequency magnetic fields in different modes of operation of magnetic resonance imaging [in Russian]. Med Tr Prom Ekol. 2019; (9):727-727. doi: 10.31089/1026-94282019-59-9-727-728.

80. Pokhodzey L.V., Rudneva E.A., Courierov N.N. Actual problems of hygienic assessment of electromagnetic fields and noise in magnetic resonance imaging departments [in Russian]. Med Tr Prom Ekol. 2019; (9):726-726. doi: 10.31089/1026-9428-2019-59-9-726-727.

81. Stam R, Yamaguchi-Sekino S Occupational exposure to electromagnetic fields from medical sources. Ind Health. 2018; 56(2):96-105. doi: 10.2486 / indhealth.2017-0112. 